\title{
Evaluation of ciprofloxacin and metronidazole encapsulated biomimetic nanomatrix gel on Enterococcus faecalis and Treponema denticola
}

Sagar N Kaushik', Jessica Scoffield², Adinarayana Andukuri', Grant C Alexander ${ }^{1}$, Taneidra Walker ${ }^{1}$, Seokgon Kim5, Sung Chul Choi ${ }^{5}$, Brigitta C Brott ${ }^{3}$, Paul D Eleazer ${ }^{4}$, Jin-Yong Lee ${ }^{6}$, Hui Wu², Noel K Childers ${ }^{2}$, Ho-Wook Jun ${ }^{1}$, Jae-Hong Park ${ }^{1,5^{*}+}$ and Kyounga Cheon ${ }^{2^{*}+}$

\begin{abstract}
Background: A triple antibiotic mixture (ciprofloxacin; CF, metronidazole; MN, and minocycline; MC) has been used for dental root canal medicaments in pulp regeneration therapy. However, tooth discolorations, cervical root fractures, and inadequate pulp-dentin formation have been reported due to the triple antibiotic regimen. Therefore, an antibiotic encapsulated biomimetic nanomatrix gel was developed to minimize the clinical limitations and maximize a natural healing process in root canal infections. In this study, minimal bacterial concentrations (MBC) of the selected antibiotics (CF and MN) were tested in 14 representative endodontic bacterial species. Then MBC of each CF and MN were separately encapsulated within the injectable self-assembled biomimetic nanomatrix gel to evaluate antibacterial level on Enterococcus faecalis and Treponema denticola.

Results: Antibiotic concentrations lower than $0.2 \mu \mathrm{g} / \mathrm{mL}$ of CF and MN demonstrated antibacterial activity on the 14 endodontic species. Furthermore, 6 different concentrations of CF and MN separately encapsulated with the injectable self-assembled biomimetic nanomatrix gel demonstrated antibacterial activity on Enterococcus faecalis and Treponema denticola at the lowest tested concentration of $0.0625 \mu \mathrm{g} / \mathrm{mL}$.

Conclusions: These results suggest that each CF and MN encapsulated within the injectable self-assembled biomimetic nanomatrix gel demonstrated antibacterial effects, which could be effective for the root canal disinfection while eliminating MC. In the long term, the antibiotic encapsulated injectable self-assembled biomimetic nanomatrix gel can provide a multifunctional antibiotic delivery method with potential root regeneration. Further studies are currently underway to evaluate the effects of combined CF and MN encapsulated within the injectable self-assembled biomimetic nanomatrix gel on clinical samples.
\end{abstract}

Keywords: Ciprofloxacin, Metronidazole, Enterococcus faecalis, Treponema denticola, Injectable self-assembled biomimetic nanomatrix gel

\section{Background}

Dental pulp tissue exposed to mechanical trauma or cariogenic processes can result in root canals and/or periapical infections, which can be treated with endodontic procedure (root canal treatment) [1]. Infected

\footnotetext{
* Correspondence: pedopjh@khu.ac.kr; kcheon@uab.edu

${ }^{\dagger}$ Equal contributors

${ }^{1}$ Department of Biomedical Engineering, University of Alabama at

Birmingham, Birmingham, AL, USA

${ }^{2}$ Department of Pediatric Dentistry, University of Alabama at Birmingham,

SDB 304B, 1720 2nd Ave S, Birmingham, AL 35294-0007, USA

Full list of author information is available at the end of the article
}

teeth with immature root structure require a root end closure treatment (apexification) by $\mathrm{Ca}(\mathrm{OH})_{2}$ or mineral trioxide aggregate [2]. Yet the apexification method has been shown to result in poor pulp-dentin tissue formation. In order to regenerate pulp-dentin tissue in the infected immature root, a revascularization procedure has been applied using a triple antibiotics mixture, ciprofloxacin $(\mathrm{CF})$, metronidazole $(\mathrm{MN})$, and minocycline $(\mathrm{MC})$, along with $\mathrm{NaOCl}$ irrigation and $\mathrm{Ca}(\mathrm{OH})_{2}$ [3-5]. However, the traditional revascularization treatment has been implicated in several adverse clinical outcomes including

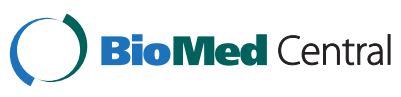

(C) 2015 Kaushik et al.; licensee BioMed Central. This is an Open Access article distributed under the terms of the Creative Commons Attribution License (http://creativecommons.org/licenses/by/4.0), which permits unrestricted use, distribution, and reproduction in any medium, provided the original work is properly credited. The Creative Commons Public Domain Dedication waiver (http://creativecommons.org/publicdomain/zero/1.0/) applies to the data made available in this article unless otherwise stated. 
tooth discoloration, cervical fracture, and inadequate pulp-dentin tissue formation [6-8].

The regenerative tissue engineering concept has grown in the field of medicine. Its main contributors include pluripotent cells, signaling molecules, and scaffold system which is to capture characteristic properties of natural extracellular matrix (ECM) which plays a key role in tissue development [9-11]. The scaffolds can be synthesized by variety of recent nanotechnology including selfassembly, electrospinning and thermal inducing phase separation characterized by biocompatibility and biodegradability $[10,12]$. Among the nanotechnology, a biomimetic nanomatrix gel is formed by self-assembled peptide amphiphiles (PAs), which consist of a hydrophilic functional peptide sequence attached to a hydrophobic alkyl tail. Due to their amphiphilic characteristics and molecular shape, PAs can self-assemble into highly ordered ECM like nanostructures in optimal $\mathrm{pH}[13,14]$. In addition, manipulative viscoelastic properties of PA structure allows for replication of the essential properties of the ECM environment [12,15-17]. Thus the biomimetic nanomatrix gel contains several functional units; scaffolding self-assembled nanofibers, injectable viscoelastic properties, encapsulation of cells or antibiotics at physiological conditions, releasing of antibiotics in a highly controlled manner, cell adhesive ligands, and enzyme-mediated degradable sites $[16,18]$. With these functional benefits, the biomimetic nanomatrix gel was considered to be applied to the regenerative endodontics; antibiotic molecules can be encapsulated within the self-assembled biomimetic nanomatrix gel to be released in controlled manner inside root canal, which can reduce the antibiotic concentrations compared to the triple antibiotic mixture; unique viscoelastic property of the nanomatrix gel enables direct injection into the infected root canal space; the ECM mimicking selfassembled PAs can promote interaction with surrounding pulp tissues. While the conventional triple mixture was mixed manually with nonfunctional and non-bioactive paste.

The goals of the successful endodontic regeneration therapy can be demonstrated by a lacking of posttreatment clinical symptoms and radiographic evidence of continued root development [3]. To achieve the goals, efficient root canal disinfection and adequate root dentin formation are proposed using antibiotics encapsulated injectable self-assembled biomimetic nanomatrix gel. In this study, minimal bactericidal concentrations (MBC) from the triple antibiotics, $\mathrm{CF}, \mathrm{MN}$ excluding $\mathrm{MC}$, were tested to determine bactericidal activity against 14 endodontic species. Augmentin (AM) was also tested as a potential alternative to $\mathrm{MC}$ to reduce the unfavorable tooth discoloration associated with the conventional triple mixture. Consequently, predetermined concentrations of the each antibiotic were encapsulated within the injectable biomimetic nanomatrix gel and evaluated its bactericidal activity on Enterococcus faecalis and Treponema denticola. E. faecalis and T. denticola were selected as the facultative and strict anaerobic species among the above 14 endodontic species.

\section{Methods}

\section{Antibiotics and agar dilution preparation}

The antibiotics, CF (Nelson Pharm Korea ${ }^{\circ}$ Seoul, Korea), MN (Cheil Jedang, Seoul, Korea) and AM (IlSung Shin Yak ${ }^{\circ}$, Seoul, Korea), were provided by powder form and mixed with propylene glycol [5]. Each antibiotic was serially diluted in 2-fold from starting concentration $5 \mu \mathrm{g} / \mathrm{mL}$ and mixed with sterilized 1.5\% agar supplemented with Brucella broth, Vitamin K1, Hemin solution, and supplemented with 5\% defibrinated sheep blood in pH 7.2 as manufacture recommended (Becton, Dickinson and Company, Franklin Lakes, NJ, USA). Two $\mathrm{mL}$ of the mixed solution of the antibiotic and the media was distributed to the each well of 24 well-plates. Positive controls were prepared with $1 \mu \mathrm{L}$ from 10 -fold serial dilution of the bacteria culture broth without antibiotics. Antibiotics without bacterial species served as the negative control. Following preparation of the controls, the plates incubated overnight at room temperature.

\section{Bacterial species and culture}

Fourteen bacteria species [19] which have been frequently observed from root canal infection were selected for the antibiotic susceptibility tests. The bacteria are Aggregatibacter actinomycetemcomitans (Aa), Fusobacterium nucleatum (Fn), Porphyromonas endodontalis (Pe), Porphyromonas gingivalis (Pg), Prevotella nigresens (Pn), Prevotella intermedia (Pi), Tennerella forsythia (Tf), Treponema denticola (Td), Enterococcus faecalis (Ef), Lactobacillus casei (Lc), Streptococcus gordonii (Sg), Streptococcus mutans (Sm), Streptococcus sobrinus (Sso), and Streptococcus sanguinis (Ssa). Each of the 14 bacterial species were incubated in anaerobic condition for 48 hours on Brucella blood agar plates; then several colonies were inoculated in suspension of $10 \mathrm{~mL}$ Brucella broth and incubated for 6 hrs anaerobically at $37^{\circ} \mathrm{C}$ as shown in the Table 1 . The bacterial density from the suspensions was adjusted with sterile Brucella broth to equivalent by the $0.5 \mathrm{McF}$ arland standard and the optical density (OD) value was adjusted to 0.1 [20]. From the adjusted broth culture of the 14 species, $1 \mu \mathrm{L}$ was dropped in 5 different locations onto prepared the 1.5\% agar in 24 well-plates within 15 minutes. Then the plates were incubated anaerobically at $37^{\circ} \mathrm{C}$ for $1-7$ days depending on the species [21].

The data was initially measured as Minimal Inhibitory Concentration (MIC); however, the MIC can be considered 
Table 1 Common bacterial species found in endodontic root canals and culture condition

\begin{tabular}{|c|c|c|c|c|}
\hline \multirow[t]{2}{*}{ Bacterial species } & \multirow[t]{2}{*}{ Source } & \multicolumn{2}{|l|}{ Media } & \multirow[t]{2}{*}{ Condition } \\
\hline & & Liquid & Solid & \\
\hline A. actinomycetemcomitans & Y4 & $\mathrm{BHI}$ broth & $\mathrm{BHI}+$ agar & $37^{\circ} \mathrm{C}, 5 \% \mathrm{CO}_{2}$ \\
\hline F. nucleatum & ATCC 23726 & $\mathrm{BHI}$ broth & $\mathrm{BHI}+$ agar & $37^{\circ} \mathrm{C}$, Anaerobic \\
\hline P. endodontalis & ATCC 35496 & Pg broth & Blood agar & $37^{\circ} \mathrm{C}$, Anaerobic \\
\hline P. gingivalis & 2561 & Pg broth & Blood agar & $37^{\circ} \mathrm{C}$, Anaerobic \\
\hline P. nigrescens & ATCC 33563 & Pg broth & Blood agar & $37^{\circ} \mathrm{C}$, Anaerobic \\
\hline P. intermedia & ATCC 25611 & Pg broth & Blood agar & $37^{\circ} \mathrm{C}$, Anaerobic \\
\hline T. forsythia & ATCC 43037 & PY borth & NAM medium & $37^{\circ} \mathrm{C}$, Anaerobic \\
\hline T. denticola & ATCC 3521 & TYGVS & TYGVS + agar & $37^{\circ} \mathrm{C}$, Anaerobic \\
\hline E. faecalis & ATCC 4083 & $\mathrm{BHI}$ broth & $\mathrm{BHI}+$ agar & $37^{\circ} \mathrm{C}$, Facultative \\
\hline L. casei & HY 2782 & MRS & MRS + agar & $37^{\circ} \mathrm{C}$, Facultative \\
\hline S. gordonii & G9B & $\mathrm{BHI}$ broth & $\mathrm{BHI}+$ agar & $37^{\circ} \mathrm{C}$, Facultative \\
\hline S. mutans & GS5 & BHI broth & $\mathrm{BHI}+$ agar & $37^{\circ} \mathrm{C}$, Facultative \\
\hline S. sobrinus & 6715 & $\mathrm{BH}$ broth & $\mathrm{BHI}+$ agar & $37^{\circ} \mathrm{C}$, Facultative \\
\hline S. sanguinis & clinical isolates & $\mathrm{BHI}$ broth & $\mathrm{BHI}+$ agar & $37^{\circ} \mathrm{C}$, Facultative \\
\hline
\end{tabular}

BHI: Brain-heart infusion, Pg: Porphyromonas gingivalis , TYGVS: tryptone-yeast extract-gelatin-volatile fatty acids-serum, MRS: deMan, Rogosa and Sharpe, NAM: N-acetylmuramic acid.

as $\mathrm{MBC}$ when it shows $99.9 \%$ of bacterial colony reduction (bactericidal effects). For bactericidal drugs, the MBC is usually the same as and generally not more than 4-fold higher than the MIC [22]. Therefore, MBCs were determined by counting colony forming units (CFUs) at $99.9 \%$ of bactericidal effect of each of the 14 species based on the anaerobe antimicrobial susceptibility testing protocol [23].

\section{Synthesis of peptide amphiphiles}

The peptide amphiphiles (PAs) were synthesized using standard Fmoc-chemistry on an Advanced Chemtech Apex 396 peptide synthesizer (AAPPTec, Louisville, KY, USA), as described before [14]. The three different peptides, Tyr-Ile-Gly-Ser-Arg, (YIGSR, cell-adhesive ligand), Lysine (KKKKK, NO donor), and Short (enhance gelation) were synthesized to be 13 amino acids long and contain the MMP-2 sensitive sequence (GTAGLIGQ) [14]. Following the synthesis, the peptides were alkylated through linkage to a 16 carbonpalmityl chain resulting in PAs: PAs C16-GTAGLIGQ-YIGSR (PA-YIGSR), C16-GTA GLIGQ-KKKKK (PA-KKKKK), and C16-GTAGLIGQ-S (PA-Short). PA-YIGSR and PA-KKKKK were dissolved in deionized water to prepare $1 \mathrm{wt} \%$ stock solutions. The $\mathrm{pH}$ of these solutions was adjusted to 7.4 using a $1 \mathrm{M}$ sodium hydroxide solution. PA-Short was dissolved in deionized water to make a $2 \mathrm{wt} \%$ stock solution. The $\mathrm{pH}$ of this solution was also adjusted to 7.4 in the same manner. PA-YIGSR and PA-KKKKK were then mixed in a ratio 9 PA-YIGSR: 1 PA-KKKKK to form PA-YK. The 9:1 ratio for PA-YK was selected due to its optimized performance in gelation as cell adhesion is significantly improved with increasing PA-YIGSR concentration as previously demonstrated [24]. Then $25 \mu \mathrm{L}$ of PA-YK and $25 \mu \mathrm{L}$ of the PA-Short solutions were placed in 12-well silicon inserts, flexiPerm ${ }^{\circ}$ (Sigma Aldrich, St. Louis, MO, USA), attached to a glass cover slide.

\section{Encapsulation of ciprofloxacin (CF) and metronidazole (MN) in the biomimetic nanomatrix gel}

After the screening of the 14 endodontic species, the antibiotics CF (GenHunter, Nashville, TN, USA) and MN (Sigma-Aldrich, St. Louis, MO, USA) were purchased and separately prepared as $5 \mu \mathrm{g} / \mathrm{mL}$ stock solutions. Then the antibiotic stock solutions were serially diluted to concentrations of $0,0.0625,0.125,0.25,0.5$ and $1 \mu \mathrm{g} /$ $\mathrm{mL}$ in $15 \mathrm{~mL}$ of DI water at $\mathrm{pH}$ 7.4. Ten $\mu \mathrm{L}$ of an aqueous solution of $0.1 \mathrm{M} \mathrm{CaCl}_{2}$ and $5 \mu \mathrm{L}$ of the prepared antibiotic solution were added to a cylindrical-shaped silicone mold flexiPerm ${ }^{\circ}$ to induce self-assembled antibiotic encapsulated within the biomimetic nanomatrix gel. The cylindrical-shaped gel was preferred for the intracanal injectable biomimetic nanomatrix gel application.

\section{Bacterial culture for $E$. faecalis and T. denticola}

E. faecalis was cultured in Todd-Hewitt broth (THB) and incubated aerobically with $37^{\circ} \mathrm{C}$ with $5 \% \mathrm{CO}_{2}$ for 24 hours. Similarly, T. denticola was cultured in New Oral Spirochete media (NOS) and grown in a Coy anaerobic chamber at $37^{\circ} \mathrm{C}$ for 24 hours. Overnight bacterial cultures were sub-cultured by diluting $1 / 100$ in THB or NOS until the bacteria reached mid-log phase. To determine CFUs, E. faecalis was serially diluted and plated on sheep blood agar (BD Falcon, Bedford, MA, USA) at $37^{\circ} \mathrm{C}$ for 24 hours. The bacterial densities from the broth 
suspensions were determined by the 0.5 McFarland standard with optical density $\left(\mathrm{OD}_{600}\right)$; E. faecalis $(6.2 \times$ $\left.10^{6} \mathrm{CFU} / \mathrm{mL}\right)$ and $T$. denticola $\left(2.0 \times 10^{9} \mathrm{CFU} / \mathrm{mL}\right)$ were used throughout the experiment [20,25]. As seen in Figure 1, the CFUs were counted by serially diluted cell suspension: $10^{-2}, 10^{-4}$ and $10^{-6}$. Ten $\mu \mathrm{L}$ of each serially diluted bacterial suspension was pipetted into an Anaerobe Blood Agar Plate (BD Falcon, San Jose, $\mathrm{CA}$ ) and spread for $24 \mathrm{hr}$ incubation. The plates were visually inspected to determine the colony morphology and counted for CFUs.

\section{Evaluation of antibacterial effects of the antibiotic} encapsulated injectable biomimetic nanomatrix gel

The prepared cylindrical nanomatrix gels were removed from the flexiPerm ${ }^{\odot}$ and placed in the center of each 24 well culture plate. One $\mathrm{mL}$ of the 24 hour-cultured THB bacteria was evenly distributed in each of the wells and incubated in aerobic or anaerobic condition, depending on the bacteria, at $37^{\circ} \mathrm{C}$ for 24 hours. Positive controls (antibiotic without nanomatrix gel) and negative controls (bacteria only) were also included as shown in Figure 2. The experiments were repeated 4 times for calculation of the mean values. ODs were used to measure bacterial loads at the variable antibiotic concentrations
(0 $\mu \mathrm{g} / \mathrm{mL}, 0.0625 \mu \mathrm{g} / \mathrm{mL}, 0.125 \mu \mathrm{g} / \mathrm{mL}, 0.25 \mu \mathrm{g} / \mathrm{mL}$, $0.5 \mu \mathrm{g} / \mathrm{mL}$ and $1 \mu \mathrm{g} / \mathrm{mL}$ ) using a spectrophotometer (Beckman Coulter DU800, Brea, CA, USA). To determine the bactericidal activity after 24 hour culture, ODs were measured by collection of $500 \mu \mathrm{L}$ from the each wells of the 24 well bacteria culture plates and measured using a disposable cuvette at a wavelength of $600 \mathrm{~nm}[26,27]$ using a spectrophotometer.

\section{Results}

Minimal bactericidal concentration (MBC) of 3 antibiotics Table 2 summarizes MBCs of the 3 antibiotics (CF, MN, and AM), respectively for the 14 species cultures. The MBCs for both CF and MN were $0.1 \mu \mathrm{g} / \mathrm{mL}$ in 6 species ( $\mathrm{Aa}, \mathrm{Fn}, \mathrm{Pe}, \mathrm{Pg}, \mathrm{Pi}$, and $\mathrm{Tf}$ ) and $0.2 \mu \mathrm{g} / \mathrm{mL}$ in 5 species (Ef, Sg, Sm, Sso, and Ssa). Meanwhile the MBC for AM was required 2 to 5 -fold higher concentrations to achieve similar effect to $\mathrm{CF}$ and $\mathrm{MN}$.

\section{The effect of ciprofloxacin (CF) and metronidazole (MN)} against facultative anaerobic $E$. faecalis

CF was shown to have dose dependent antibacterial effect against the three different $E$. faecalis densities at the lowest concentration of $0.0625 \mu \mathrm{g} / \mathrm{mL}$ (Figure 3A). Figure $3 \mathrm{~B}$ illustrated that the $\mathrm{CF}$ encapsulated biomimetic

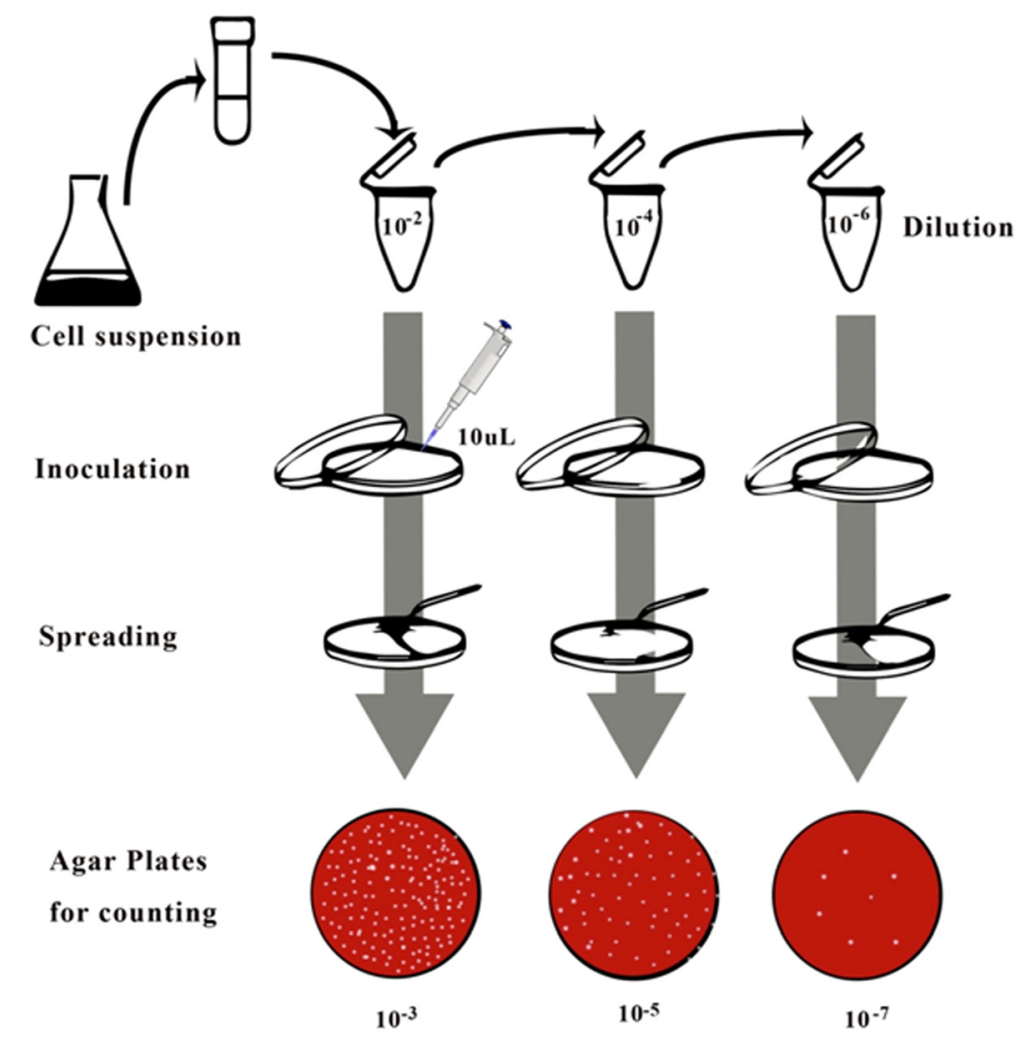

Figure 1 Bacterial morphology and colony forming units (CFUs)/mL. Bacterial morphology and CFUs were verified with serial dilutions followed by sheep blood agar culture. Optical Density $(600 \mathrm{~nm})$ measured $10^{-4}$ dilution tube. 


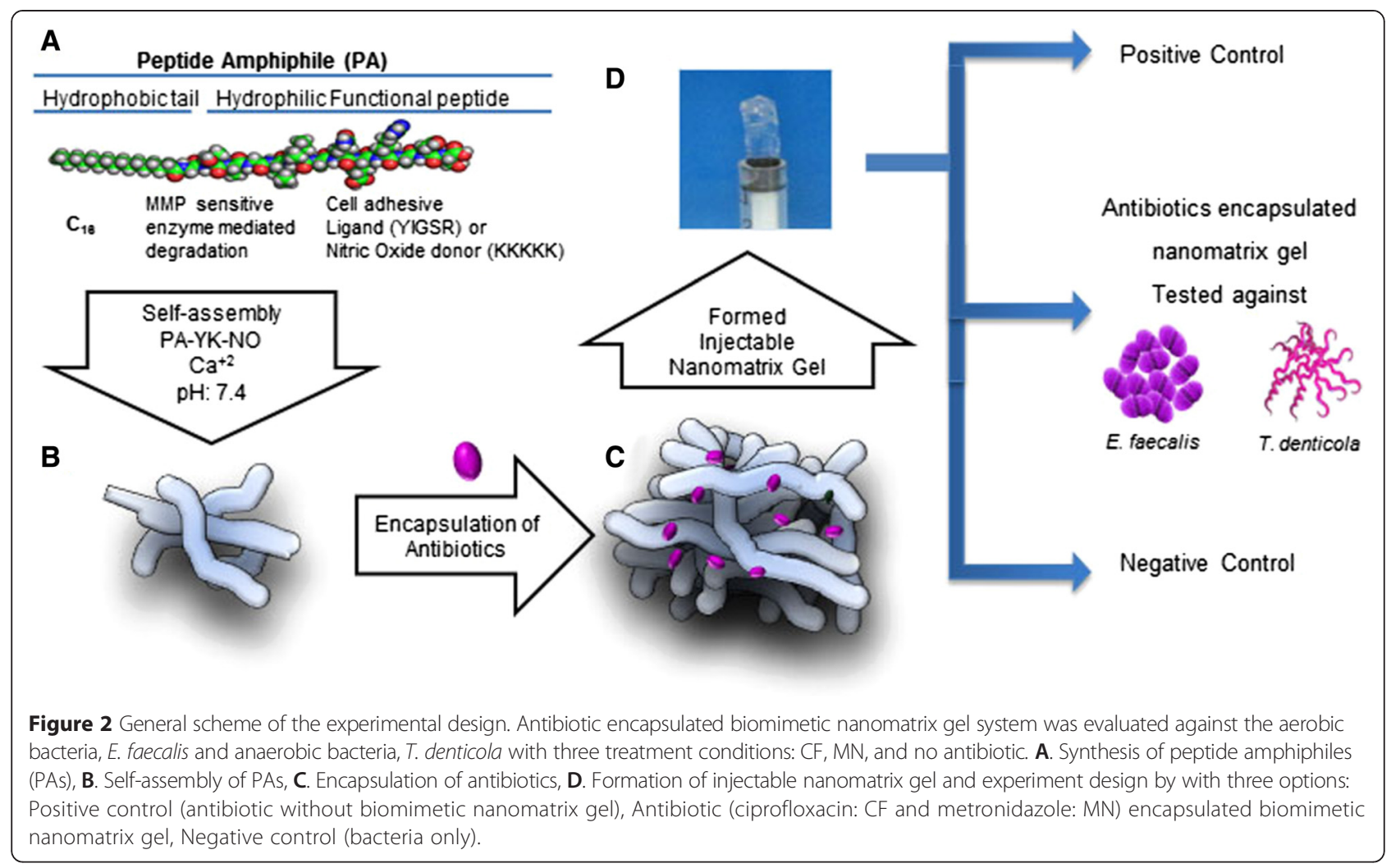

nanomatrix gel was tested in the three different $E$. faecalis densities and had similar antibacterial effects as CF without biomimetic nanomatrix gel.

The effect of the antibiotic MN was studied on the same densities of E. faecalis as the CF experiments. In Figure 4, interestingly the antibiotic $\mathrm{MN}$ was not as effective on $E$. faecalis as CF was. The results of the MN encapsulated with nanomatrix gel in same bacterial densities also did not show antibacterial effect (Figure 4B).

\section{The effect of ciprofloxacin and metronidazole against anaerobic $T$. denticola}

As seen in Figure 5A, the antibiotic CF against $T$. denticola displayed complete bactericidal effect in the different densities $\left(2.0 \times 10^{6} \mathrm{CFU} / \mathrm{mL}\right.$ and $2.0 \times 10^{7} \mathrm{CFU} /$ $\mathrm{mL}$ ) at the concentration of $0.0625 \mu \mathrm{g} / \mathrm{mL}$ without biomimetic nanomatrix gel. Similarly, the CF encapsulated with biomimetic nanomatrix gel (Figure 5B) showed that the antibacterial activity is effective at $0.0625 \mu \mathrm{g} / \mathrm{mL}$ concentration to all bacterial densities including $2.0 \times$ $10^{8} \mathrm{CFU} / \mathrm{mL}$.

The antibacterial effect of MN was seen on the bacterium $T$. denticola with varying densities as shown in Figure 6. Bactericidal effects were shown at $0.0625 \mu \mathrm{g} /$ $\mathrm{mL}$ of $\mathrm{MN}$ without encapsulation in an injectable selfassembled biomimetic nanomatrix gel (Figure 6A) and with encapsulation in an injectable self-assembled biomimetic nanomatrix gel (Figure 6B).

\section{Discussion}

\section{Antimicrobial susceptibility test}

Table 2 displays the MBCs of the three antibiotics (CF, $\mathrm{MN}$, and $\mathrm{AM})$. CF interferes with DNA function in bacteria such as aerobic and anaerobic gram-positive bacteria and several mycobacterium species [28]. MN interferes with bacterial DNA of gram-negative anaerobic bacilli [29]. AM, a combination of amoxicillin and clavulanate potassium, has shown great efficacy in dental infection due to its broad spectrum and few adverse effects $[30,31]$. AM was tested instead of MC which is the most effective component; although its adverse effect of tooth discoloration is detested in clinical applications [6]. When the MBCs were converted to a ratio, it was observed as 1:1:5 (CF: MN: AM) respectively in 11 species (Aa, Fn, Pe, Pg, Pi, Tf, Ef, Sg, Sm, Sso, and Ssa), which ratio reflect that AM required 2 to 5-fold higher concentrations overall to achieve similar bactericidal effects compared to CF and MN. Therefore, AM was removed from the nanomatrix encapsulation study due to concern of increased concentration dosage affecting the patients' health. CF and MN have successfully been used in intra-canal medicaments without incorporating a third component, $\mathrm{MC}$, and are commonly referred to as double antibiotic paste [32]. Furthermore, our results indicate that $\mathrm{CF}$ and $\mathrm{MN}$ can be effective with a 1:1 ratio concentration than the triple antibiotic ratio (1:3) and agreed to the previous study [32]. 
Table 2 Minimal bactericidal concentration (MBC) of 3 antibiotics measured for 14 bacterial species

\begin{tabular}{|c|c|c|c|c|c|}
\hline \multirow{2}{*}{$\begin{array}{l}\text { Species } \\
\text { A. actinomycetemcomitans }\end{array}$} & \multicolumn{2}{|c|}{$\mathrm{MBC}(\mu \mathrm{g} / \mathrm{mL})$} & \multirow{2}{*}{$\frac{\text { Species }}{\text { T. denticola }}$} & \multicolumn{2}{|c|}{$\mathrm{MBC}(\mu \mathrm{g} / \mathrm{mL})$} \\
\hline & CF & 0.1 & & $\mathrm{CF}$ & 0.1 \\
\hline & MN & 0.1 & & MN & 0.25 \\
\hline & $A M$ & 0.5 & & AM & 0.5 \\
\hline \multirow[t]{3}{*}{ F. nucleatum } & CF & 0.1 & E. faecalis & CF & 0.2 \\
\hline & MN & 0.1 & & MN & 0.2 \\
\hline & AM & 0.5 & & $\mathrm{AM}$ & 1 \\
\hline \multirow[t]{3}{*}{ P. endodontalis } & CF & 0.1 & L. casei & CF & 1 \\
\hline & MN & 0.1 & & MN & 0.5 \\
\hline & AM & 0.5 & & AM & 2 \\
\hline \multirow[t]{3}{*}{ P. gingivalis } & CF & 0.1 & S. gordonii & CF & 0.2 \\
\hline & MN & 0.1 & & MN & 0.2 \\
\hline & $A M$ & 0.5 & & AM & 1 \\
\hline \multirow[t]{3}{*}{ P. nigresens } & CF & 0.25 & S. mutans & CF & 0.2 \\
\hline & MN & 0.25 & & MN & 0.2 \\
\hline & AM & 0.5 & & AM & 1 \\
\hline \multirow[t]{3}{*}{ P.intermedia } & CF & 0.1 & S. sobrinus & CF & 0.2 \\
\hline & MN & 0.1 & & MN & 0.2 \\
\hline & $A M$ & 0.5 & & AM & 1 \\
\hline \multirow[t]{3}{*}{ T. forsythia } & $\mathrm{CF}$ & 0.1 & S. sanguinis & $C F$ & 0.2 \\
\hline & MN & 0.1 & & MN & 0.2 \\
\hline & $A M$ & 0.5 & & AM & 1 \\
\hline
\end{tabular}

CF: ciprofloxacin, MN: metronidazole, AM: Augmentin, MBC: minimal bactericidal concentration.
Recent in vitro studies regarding the cytotoxicity of the single antibiotic have shown that the concentrations of $0.024 \mu \mathrm{g} / \mathrm{mL}$ maintained dental pulp cell viability for during 7 days [33] and more than $1 \mathrm{mg} / \mathrm{mL}$ can be a harmful effect on dental pulp stem cell [34]. This supports our results which demonstrated between $0.0625 \mu \mathrm{g} / \mathrm{mL}$ and $1 \mu \mathrm{g} / \mathrm{mL}$ for a single antibiotic bactericidal effect. Although our data is preliminary, it suggests potential benefits to patients by reducing unfavorable antibiotic complications. Further investigations will be required to confirm our findings in clinical samples, which may include a complex of endodontic bacteria.

Table 2 results also show that the latter 5 species (Ef, $S g, S m, S s o$, and $S s a)$ among the 11 species with a 1:1:5 $\mathrm{MBC}$ ratio were all facultative anaerobes and required an antibiotic concentration that was double that of the other 6 species $(A a, F n, P e, P g, P i$ and $T f)$. This may be due to the survival capability of the facultative anaerobes under the anaerobic environment. Particularly, E. faecalis is known as normal commensal flora in the human digestive system and often causes nosocomial infections and has been shown to display antibiotic resistance. It is also known as one of the main pathogens causing recurrent endodontic infections [35].

\section{Selection of $E$. faecalis and $T$. denticola}

Infective dental root canal consisted of a variety of bacteria; among the endodontic microbiota, E. faecalis and T. denticola were selected as an initial microorganism to be tested for antibiotic encapsulated self-assembled biomimetic nanomatrix gel. E. faecalis, a gram-positive aerobic cocci and $T$. denticola, a gram-negative anaerobic fusiform rod, are often found in endodontic infections

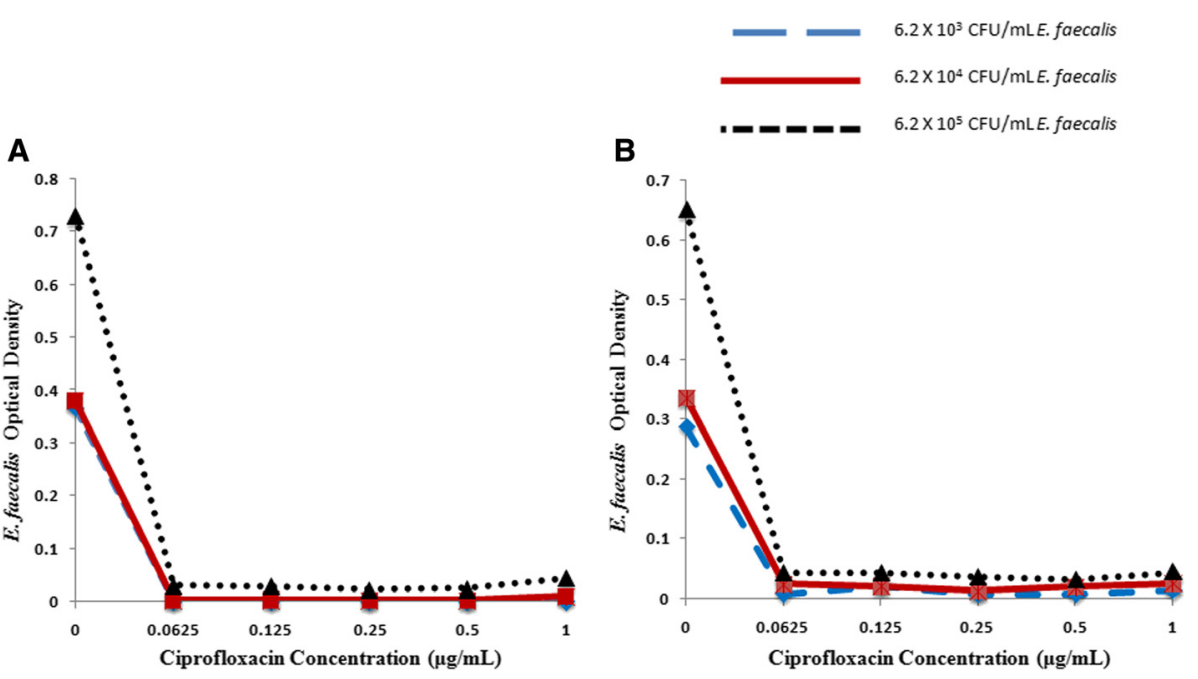

Figure 3 The effect of ciprofloxacin (CF) against E. faecalis. Antibacterial effect of CF was measured in varying concentrations of $0 \mu \mathrm{g} / \mathrm{mL}$, $0.0625 \mu \mathrm{g} / \mathrm{mL}, 0.125 \mu \mathrm{g} / \mathrm{mL}, 0.25 \mu \mathrm{g} / \mathrm{mL}, 0.5 \mu \mathrm{g} / \mathrm{mL}$ and $1 \mu \mathrm{g} / \mathrm{mL}$ against $E$. faecalis in concentrations of $6.2 \times 10^{3} \mathrm{CFU} / \mathrm{mL}, 6.2 \times 10^{4} \mathrm{CFU} / \mathrm{mL}$ and $6.2 \times 10^{5} \mathrm{CFU} / \mathrm{mL}$. A. Without nanomatrix gel, B. With antibiotic encapsulated in nanomatrix gel. 

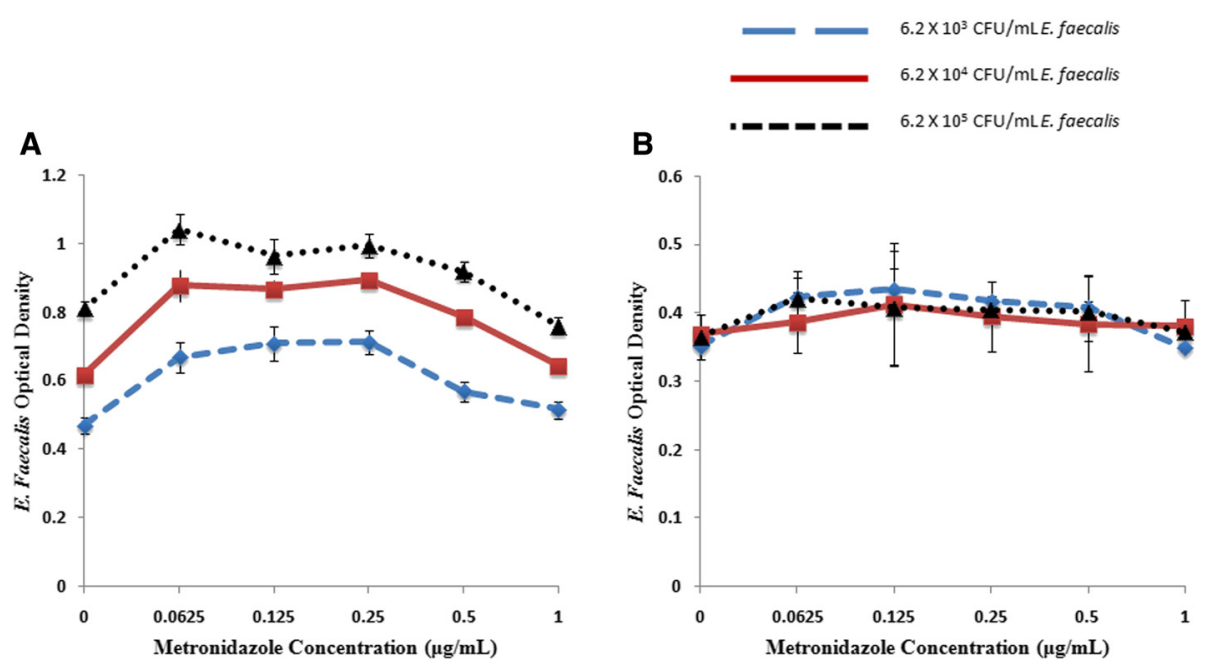

Figure 4 The effect of metronidazole $(\mathrm{MN})$ against $E$. faecalis. Antibacterial effect of $\mathrm{MN}$ was measured in varying concentrations of $0 \mu \mathrm{g} / \mathrm{mL}$, $0.0625 \mu \mathrm{g} / \mathrm{mL}, 0.125 \mu \mathrm{g} / \mathrm{mL}, 0.25 \mu \mathrm{g} / \mathrm{mL}, 0.5 \mu \mathrm{g} / \mathrm{mL}$ and $1 \mu \mathrm{g} / \mathrm{mL}$ on E. faecalis in concentrations of $6.2 \times 10^{3} \mathrm{CFU} / \mathrm{mL}, 6.2 \times 10^{4} \mathrm{CFU} / \mathrm{mL}$ and $6.2 \times 10^{5} \mathrm{CFU} / \mathrm{mL}$. A. Without nanomatrix gel, B. With antibiotic encapsulated in nanomatrix gel.

and commonly used to evaluate endodontic disinfectants $[36,37]$. As a pilot study, these two species in vitro studies demonstrated the optimal bactericidal concentrations of antibiotic encapsulated injectable self-assembled biomimetic nanomatrix gel delivery system.

\section{Antibiotic encapsulation within the injectable self-assembled biomimetic nanomatrix gel}

As observed in Figures 3 and 5, when CF was encapsulated in the injectable self-assembled biomimetic nanomatrix gel (Figures 3B and 5B), CF was successfully released from the injectable self-assembled biomimetic nanomatrix gel and demonstrated similar bactericidal effect as antibiotic itself. This indicated that the injectable selfassembled biomimetic nanomatrix gel did not restrict the release and function of $\mathrm{CF}$ and also possibly suggests a sustained release of antibiotic from the injectable selfassembled biomimetic nanomatrix gel, which is effective against residual root canal bacteria. The results of Figure 5B also indicated that a sustained release of antibiotic via self-assembled injectable biomimetic nanomatrix gel promote a greater bactericidal effect than one time release of the antibiotics as seen in Figure 5A. Interestingly, the results of MN against E. faecalis (Figure 4A

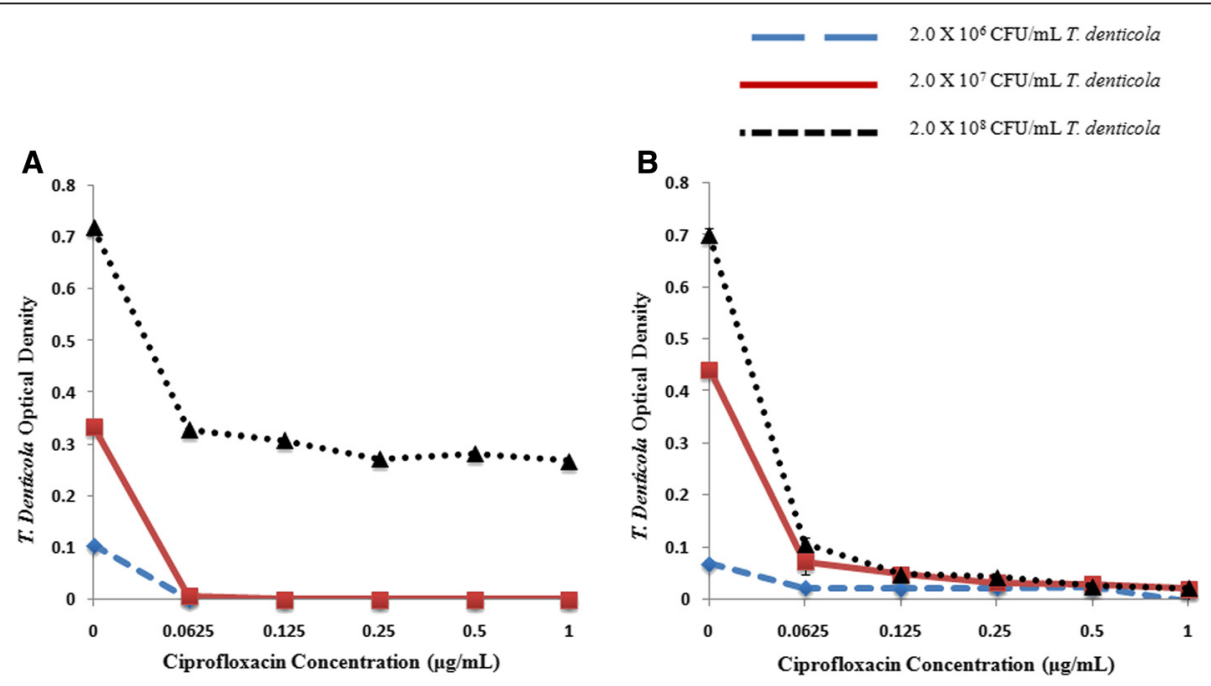

Figure 5 The Effect of ciprofloxacin (CF) against T. denticola. Antibacterial effect of CF was measured in varying concentrations of $0 \mu \mathrm{g} / \mathrm{mL}$, $0.0625 \mu \mathrm{g} / \mathrm{mL}, 0.125 \mu \mathrm{g} / \mathrm{mL}, 0.25 \mu \mathrm{g} / \mathrm{mL}, 0.5 \mu \mathrm{g} / \mathrm{mL}$ and $1 \mu \mathrm{g} / \mathrm{mL}$ on T. denticola in concentrations of $2.0 \times 10^{6} \mathrm{CFU} / \mathrm{mL}, 2.0 \times 10^{7} \mathrm{CFU} / \mathrm{mL}$ and $2.0 \times 10^{8} \mathrm{CFU} / \mathrm{mL}$. A. Without nanomatrix gel, B. With antibiotic encapsulated in nanomatrix gel. 

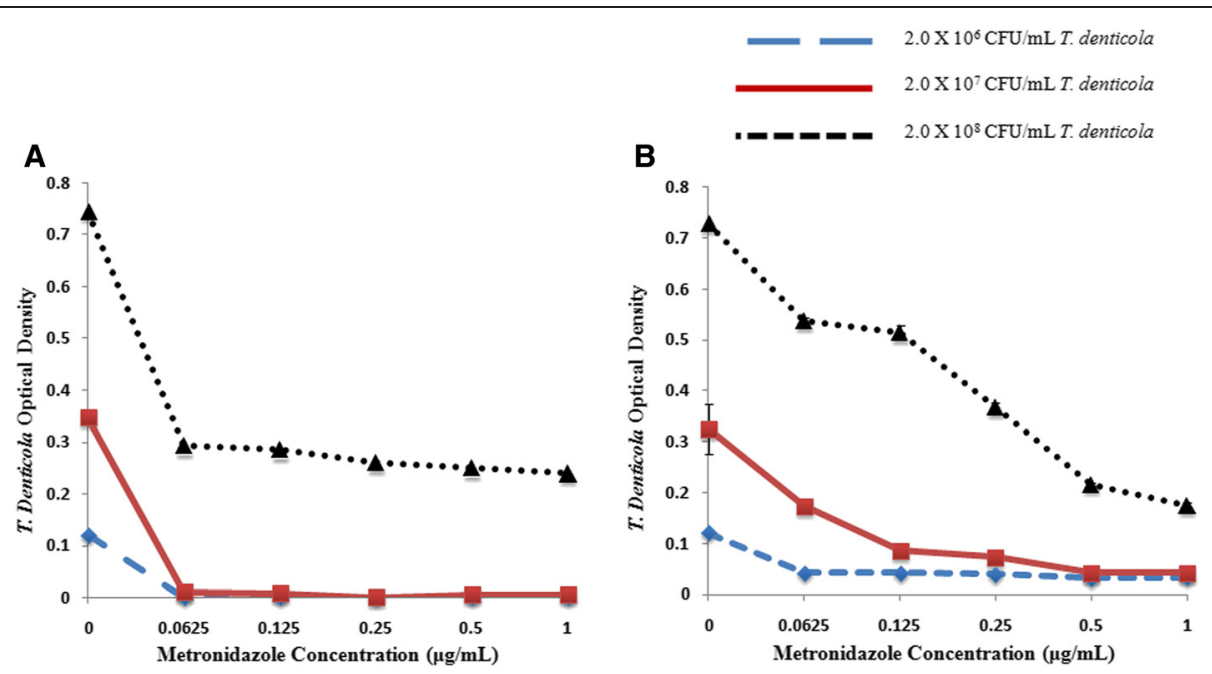

Figure 6 The Effect of metronidazole (MN) against T. denticola. Antibacterial effect of $\mathrm{MN}$ was measured in varying concentrations of $0 \mu \mathrm{g} / \mathrm{mL}$, $0.0625 \mu \mathrm{g} / \mathrm{mL}, 0.125 \mu \mathrm{g} / \mathrm{mL}, 0.25 \mu \mathrm{g} / \mathrm{mL}, 0.5 \mu \mathrm{g} / \mathrm{mL}$ and $1 \mu \mathrm{g} / \mathrm{mL}$ on T. denticola in concentrations of $2.0 \times 10^{6} \mathrm{CFU} / \mathrm{mL}, 2.0 \times 10^{7} \mathrm{CFU} / \mathrm{mL}$ and $2.0 \times 10^{8} \mathrm{CFU} / \mathrm{mL}$. A. Without nanomatrix gel, B. With antibiotic encapsulated in nanomatrix gel.

and B) demonstrated no bactericidal effects on both with and without injectable self-assembled biomimetic nanomatrix gel; this reflected that MN may not be an effective antibiotic choice for facultative anaerobic bacteria [38]. "In Figure 4B, the condition of the culture media and $E$. faecalis together may interact with the nanomatrix gel and affect the OD values of the experiment and this culture condition will be investigated further in the future experiment." However, MN may be the effective bactericidal agent in a complex of bacteria from the root canal infection, which represents most of anaerobic bacteria. When MN encapsulated injectable self-assembled biomimetic nanomatrix gel was tested against $T$. denticola (Figure 6A and B); bactericidal effect has shown successfully in the two lower $T$. denticola densities $(2.0 \times$ $10^{6} \mathrm{CFU} / \mathrm{mL}$ and $\left.2.0 \times 10^{7} \mathrm{CFU} / \mathrm{mL}\right)$. In the density of $2.0 \times 10^{8} \mathrm{CFU} / \mathrm{mL}, T$. denticola did not portray complete bactericidal activity and this may be relatively low $\mathrm{MN}$ concentrations compare to the bacterial load.

The key concept of our study is that the self-assembled PAs can be mixed with antibiotics as a direct injectable material into the infected root canal, which will provide aseptic root canal and further provide a semi-natural ECM environment. Although cellular viability of the biomimetic nanomatrix gel for the dental pulp tissue has not been studied yet; other studies have successfully shown excellent cellular biocompatibility, high level of cell confluence, and cell migration in cardiac tissues [16,39]. Our current study will be an important fundamental step to assess not only the effectiveness of MN and CF on infectious root canal bacteria, but also the potential development of the direct injectable self-assembled biomimetic nanomatrix gel to treat endodontic infections including necrotic immature teeth. As a next step, 1:1 combination of CF: $\mathrm{MN}$ encapsulated within injectable self-assembled biomimetic nanomatrix gel will be tested for a complex of endodontic root canal bacteria from patient samples in vitro and in vivo experiments. In addition, the characteristics of antibiotic release from the biomimetic nanomatrix gels will be studied to explain the duration and intensity of the antibiotic effects.

\section{Conclusions}

Concentrations $(0.0625-0.25 \mu \mathrm{g} / \mathrm{mL})$ of each CF and $\mathrm{MN}$ encapsulated within the injectable biomimetic nanomatrix gel successfully demonstrated antibacterial activity on E. faecalis and T. denticola. The proposed antibiotic encapsulated injectable biomimetic nanomatrix gel suggested an effective disinfecting and preconditioning root canal treatment with numerous potential benefits as innovative endodontic materials.

\section{Abbreviations}

CF: Ciprofloxacin; MN: Metronidazole; MC: Minocycline; ECM: Extracellular matrix; PAs: Peptide amphiphiles; MBC: Minimal bactericidal concentration; OD: Optical density; MIC: Minimal inhibitory concentration; CFUs: Colony forming units; THB: Todd-Hewitt broth; NOS: New Oral Spirochete media.

\section{Competing interests}

The authors declare that they have no competing interests.

\section{Authors' contributions}

SNK was responsible conducting the experiments for the injectable selfassembled biomimetic nanomatrix gel and the two bacterial strains with the antibiotics. He was also responsible for initial literature review and writing. JS was responsible for helping design and conduct all bacterial experiments with the injectable self-assembled biomimetic nanomatrix gel. AA was responsible for helping design the injectable self-assembled biomimetic nanomatrix gel components. GCA was responsible for overseeing SNK and TW, synthesizing PAs, and a contributor in the editing of the paper. TW was responsible for the Abstract and Introduction and a major contributor in 
the editing of the paper. SK was responsible in carrying out the initial 14 bacterial strains experiment. SCC was responsible in carrying out the initial 14 bacterial strains experiment. BCB was responsible for the project design and consultation. PDE was responsible for the project consultation. JYL was responsible in carrying out the initial 14 bacterial strains experiment as a dental microbiology. HW was responsible for the project consultation in dental microbiology. NKC was responsible for the project consultation and editing. HWJ was responsible in overseeing the injectable self-assembled biomimetic nanomatrix gel creation in experiment and directing the overall paper organization as well as the topics. He was a major contributor to the editing of the paper. JHP was responsible in overseeing the initial 14 bacterial strains experiment. KC was responsible for directing the overall paper organization as well as the topics. She also played a major part in the editing of the paper and overlooking the bacterial strains with the injectable self-assembled biomimetic nanomatrix gel portion of the experiments. All authors read and approved the final manuscript.

\section{Acknowledgements}

This study was supported by NIH Loan Repayment Program for KC, UAB School of Engineering Undergraduate Research Award for SNK, National Science Foundation Career Award (CBET-0952974) and National Institute of Health (1R01HL125391 and 1R03EB017344-01) for HWJ, and the National Research Foundation (NRF2009-007419) of Korea for JHP.

\section{Author details}

${ }^{1}$ Department of Biomedical Engineering, University of Alabama at Birmingham, Birmingham, AL, USA. ²Department of Pediatric Dentistry, University of Alabama at Birmingham, SDB 304B, 1720 2nd Ave S, Birmingham, AL 35294-0007, USA. ${ }^{3}$ Cardiovascular Division, School of Medicine, University of Alabama at Birmingham, Birmingham, AL, USA. ${ }^{4}$ Department of Endodontics, University of Alabama at Birmingham, Birmingham, AL, USA. ${ }^{5}$ Department of Pediatric Dentistry, School of Dentistry, Kyung Hee University, Seoul, Korea. ${ }^{6}$ Department of Maxillofacial Biomedical Engineering, Kyung Hee University, Seoul, Korea.

Received: 3 March 2015 Accepted: 2 April 2015

\section{Published online: 01 June 2015}

\section{References}

1. Huang GT. Dental pulp and dentin tissue engineering and regeneration: advancement and challenge. Front Biosci (Elite Ed). 2011;3:788-800.

2. Damle SG, Bhattal H, Loomba A. Apexification of anterior teeth: a comparative evaluation of mineral trioxide aggregate and calcium hydroxide paste. J Clin Pediatr Dent. 2012;36:263-8.

3. Bose $R$, Nummikoski $P$, Hargreaves $K$. A retrospective evaluation of radiographic outcomes in immature teeth with necrotic root canal systems treated with regenerative endodontic procedures. J Endod. 2009:35:1343-9.

4. Banchs F, Trope M. Revascularization of immature permanent teeth with apical periodontitis: new treatment protocol? J Endod. 2004;30:196-200.

5. Hoshino E, Kurihara-Ando N, Sato I, Uematsu H, Sato M, Kota K, et al. In-vitro antibacterial susceptibility of bacteria taken from infected root dentine to a mixture of ciprofloxacin, metronidazole and minocycline. Int Endod J. 1996;29:125-30.

6. Reynolds K, Johnson JD, Cohenca N. Pulp revascularization of necrotic bilateral bicuspids using a modified novel technique to eliminate potential coronal discolouration: a case report. Int Endod J. 2009:42:84-92.

7. Schmoldt SJ, Kirkpatrick TC, Rutledge RE, Yaccino JM. Reinforcement of simulated immature roots restored with composite resin, mineral trioxide aggregate, gutta-percha, or a fiber post after thermocycling. J Endod. 2011:37:1390-3.

8. Shimizu E, Jong G, Partridge N, Rosenberg PA, Lin LM. Histologic observation of a human immature permanent tooth with irreversible pulpitis after revascularization/regeneration procedure. J Endod. 2012;38:1293-7.

9. Langer R, Vacanti JP. Tissue engineering. Science. 1993;260:920-6.

10. Albuquerque MT, Valera MC, Nakashima M, Nor JE, Bottino MC. Tissueengineering-based strategies for regenerative endodontics. J Dent Res. 2014;93:1222-31.

11. Huang GT. Pulp and dentin tissue engineering and regeneration: current progress. Regen Med. 2009;4:697-707.
12. Anderson J, Patterson J, Vines J, Javed A, Gilbert S, Jun H. Biphasic peptide amphiphile nanomatrix embedded with hydroxyapatite nanoparticles for stimulated osteoinductive response. ACS Nano. 2011;5:9463-79.

13. Anderson JM, Andukuri A, Lim D, Jun HW. Modulating the gelation properties of self-assembling peptide amphiphiles. ACS Nano. 2009;9:3447-54.

14. Jun HW, Paramonov S, Hartgerink JD. Biomimetic self-assembled nanofibers. Soft Matter. 2006;2:177-81.

15. Jun HW, Paramonov SE, Dong H, Forraz N, McGuckin C, Hartgerink JD. Tuning the mechanical and bioresponsive properties of peptide-amphiphile nanofiber networks. J Biomater Sci, Polym Ed. 2008;19:665-76.

16. Andukuri A, Kushwaha M, Tambralli A, Anderson J, Dean D, Berry J, et al. A hybrid biomimetic nanomatrix composed of electrospun polycaprolactone and bioactive peptide amphiphiles for cardiovascular implants. Acta Biomater. 2011;7:225-33.

17. Jun HW, Yuwono V, Paramonov SE, Hartgerink JD. Enzyme-mediated degradation of peptide-amphiphile nanofiber networks. Adv Mater. 2005;17:2612-7

18. Kushwaha M, Anderson JM, Bosworth CA, Andukuri A, Minor WP, Lancaster Jr JR, et al. A nitric oxide releasing, self assembled peptide amphiphile matrix that mimics native endothelium for coating implantable cardiovascular devices. Biomaterials. 2010;31:1502-8.

19. Sassone LM, Fidel RA, Faveri M, Guerra R, Figueiredo L, Fidel SR, et al. A microbiological profile of symptomatic teeth with primary endodontic infections. J Endod. 2008;34:541-5.

20. McFarland J. The nephelometer: an instrument for estimating the numbers of bacteria in suspensions used for calculating the opsonic index and for vaccines. J Am Med Assoc. 1907:XLIX:1176-8.

21. Rankin ID. MIC testing. In: Coyle MB, editor. Manual of antimicrobial susceptibility testing, American Society of Microbiology. 2005. p. 53-62.

22. Levison ME. Pharmacodynamics of antimicrobial drugs. Infect Dis Clin North Am. 2004;18:451-65.

23. Schwalbe R, Steele-Moore L, Goodwin AC. Antimicrobial Susceptibility Testing Protocols. Boca Raton, FL: CRC Press; 2007.

24. Andukuri A, Sohn Y, Anakwenze C, Lim D, Brott B, Yoon Y, et al. Enhanced human endothelial progenitor cell adhesion and differentiation by a bioinspired multifunctional nanomatrix. Tissue Eng Part C Meth. 2013;19:375-85.

25. Forbes BA, Sahm DF, Weissfeld AS. Bailey \& Scott's diagnostic microbiology. 10th ed. St. Louis: Mosby, Inc.; 1998

26. Shapiro E, Baneyx F. Stress-based identification and classification of antibacterial agents: second-generation Escherichia coli reporter strains and optimization of detection. Antimicrob Agents Chemother. 2002;46:2490-7.

27. Stubbings WJ, Bostock JM, Ingham E, Chopra I. Assessment of a microplate method for determining the post-antibiotic effect in Staphylococcus aureus and Escherichia coli. J Antimicrob Chemother. 2004:54:139-43

28. Wade WG. In-vitro activity of ciprofloxacin and other agents against oral bacteria. J Antimicrob Chemother. 1989:24:683-7.

29. Greenstein $\mathrm{G}$. The role of metronidazole in the treatment of periodontal diseases. J Periodontol. 1993;64:1-15.

30. Lewis MA, Carmichael F, MacFarlane TW, Milligan SG. A randomised trial of co-amoxiclav (Augmentin) versus penicillin $\mathrm{V}$ in the treatment of acute dentoalveolar abscess. Br Dent J. 1993;175:169-74.

31. Poveda Roda R, Bagan JV, Sanchis Bielsa JM, Carbonell Pastor E. Antibiotic use in dental practice. A review. Med Oral Patol Oral Cir Bucal. 2007:12:E186-92.

32. Hargreaves KM, Diogenes A, Teixeira FB. Treatment options: biological basis of regenerative endodontic procedures. J Endod. 2013;39:S30-43.

33. Chuensombat S, Khemaleelakul S, Chattipakorn S, Srisuwan T. Cytotoxic effects and antibacterial efficacy of a 3-antibiotic combination: an in vitro study. J Endod. 2013;39:813-9.

34. Labban N, Yassen $G$, Windsor L, Platt J. The direct cytotoxic effects of medicaments used in endodontic regeneration on human dental pulp cells. Dent Traumatol. 2014;30:429-34.

35. Vidana $\mathrm{R}$, Sullivan A, Billstrom $H$, Ahlquist M, Lund B. Enterococcus faecalis infection in root canals - host-derived or exogenous source? Lett Appl Microbiol. 2011;52:109-15.

36. Murad CF, Sassone LM, Faveri M, Hirata Jr R, Figueiredo L, Feres M. Microbial diversity in persistent root canal infections investigated by checkerboard DNA-DNA hybridization. J Endod. 2014;40:899-906. 
37. Martinho F, Leite F, Nascimento G, Cirelli J, Gomes B. Clinical investigation of bacterial species and endotoxin in endodontic infection and evaluation of root canal content activity against macrophages by cytokine production Clin Oral Invest. 2014;18:2095-102.

38. Hoentjen F, Harmsen HJ, Braat H, Torrice CD, Mann BA, Sartor RB, et al. Antibiotics with a selective aerobic or anaerobic spectrum have different therapeutic activities in various regions of the colon in interleukin 10 gene deficient mice. Gut. 2003;52:1721-7.

39. Ban K, Park HJ, Kim S, Andukuri A, Cho KW, Hwang JW, et al. Cell therapy with embryonic stem cell-derived cardiomyocytes encapsulated in injectable nanomatrix gel enhances cell engraftment and promotes cardiac repair. ACS Nano. 2014;8:10815-25

\section{Submit your next manuscript to BioMed Central and take full advantage of:}

- Convenient online submission

- Thorough peer review

- No space constraints or color figure charges

- Immediate publication on acceptance

- Inclusion in PubMed, CAS, Scopus and Google Scholar

- Research which is freely available for redistribution 